This manuscript is a preprint that was been submitted for publication in International Journal of Rock Mechanics and Mining Sciences. Please note that, as of November 2019, the manuscript remains under peer review and has yet to be formally accepted for publication. Subsequent versions of this manuscript may have slightly different content. If accepted, the final version of this manuscript will be available via the 'Peer-reviewed Publication DOI' link on the right hand side of the eartharxiv.org webpage for this document.

Please feel free to contact any of the authors; we welcome feedback. 


\title{
Simulating Electropulse Fracture of Granitic Rock
}

\author{
Stuart D.C. Walsh ${ }^{\mathrm{a}}$, Daniel Vogler ${ }^{\mathrm{b}}$ \\ ${ }^{a}$ Monash University, Department of Civil Engineering, Melbourne, Australia \\ ${ }^{b}$ ETH Zurich, Geothermal Energy and Geofluids group, Institute of Geophysics, Zurich, \\ Switzerland
}

\begin{abstract}
Electropulse treatments employ a series of high-voltage discharges to break rock into small fragments. As these methods are particularly suited to fracturing hard brittle rocks, electropulse treatments can serve to enhance or substitute for more traditional mechanical approaches to drilling and processing of these materials. Nevertheless, while these treatments have the potential to improve hard-rock operations, the coupled electro-mechanical processes responsible for damaging the rock are poorly described. The lack of accurate models for these processes increases the difficulty of designing, controlling and optimizing tools that employ electropulse treatments and limits their range of application.

This paper describes a new modeling method for studying electropulse treatments in geotechnical operations. The multiphysics model simulates the passage of the pulse, electrical breakdown in the rock, and the mechanical response at the grain-scale. It also accounts for the contributions from different minerals and porosities, allowing the effect of material composition to be considered. In so doing, it provides a means to investigate the different physical and operational factors influencing electropulse treatments.
\end{abstract}

Keywords: Hard-rock, Plasma drilling, Fracture, Numerical modelling, Thermo-Electro-Mechanics

Email addresses: stuart.walsh@monash.edu (Stuart D.C. Walsh), davogler@ethz.ch (Daniel Vogler) 


\section{Introduction}

Hard rocks are commonly encountered in many mineral and energy operations: metalliferous mining; geothermal drilling; deep-borehole disposal of nuclear waste; and basaltic carbon sequestration - to name but a few. While conventional drilling and cutting techniques based on mechanical means are effective in low- to mid-strength rocks (e.g. sandstones and shales), they are less efficient in hard rock (granites, basalts and quarzites). The increased tool wear and lower penetration rates associated with hard rock operations can have significant detrimental economic impacts. For example, drilling may account for up to $80 \%$ of upfront costs in geothermal operations [1].

Electropulse treatments employing high-voltage discharges can act to enhance or substitute for more traditional mechanical approaches to processing hard rock. Pulsed electric power can reduce specific energy consumption, and thereby decrease overall costs $[2,3]$. Moreover, such treatments are capable of enabling new hard-rock processing methodologies: improving mining efficiencies by allowing faster, more precise cutting operations in-place of slower drill \& blast mining; and providing remediation for geothermal wells via slotting and cavity formation. As a result, high voltage pulses have also been used for drilling and mining applications $[4,5,6,7,8]$, and in civil engineering demolition and recycling operations $[9,3,10]$. The effect of high voltages on rock is also of interest in the study of fulgurites - rock formations produced as a result of lightning strikes [11].

The high voltage pulses employed in electropulse methods fragment or disintegrate the rock mass when electric breakdown occurs within the solid $[4,12,13,14]$. The pulses are transferred to the rock mass with a tool head consisting of an arrangement of electrodes. A liquid dielectric is commonly used (e.g. drilling mud) to prevent breakdown occurring in the fluid between the electrodes - rather than through the rock mass as desired. The tool head is submerged in the liquid dielectric, which also serves to transport broken material away from the rock surface. It is important to note the dependence of breakdown voltage on the voltage ramp rise time, as the breakdown field strength of the liquid is only lower than rock if the voltage rise is below a certain threshold (around 500 ns or less for water, for example [3]). The disintegration of the rock mass is a function of the onset and duration of the voltage pulses, insitu stresses and the electro-chemical properties of the rock matrix.

Drilling and cutting with electric pulses requires less energy compared 
with conventional techniques as the rock fails in tension. This yields estimated energy rates of 100 to $200 \mathrm{~J} / \mathrm{m}^{3}$ in contrast to 600 to $950 \mathrm{~J} / \mathrm{m}^{3}$ for rotary drilling [2]. Moreover, as no mechanical force is exerted by the tool onto the rock, it results in less wear, tool damage and time lost to replace damaged parts [15]. Additionally, the process enables more complex drill patterns, such as perpendicular drilling and cutting, that are notoriously difficult to achieve with conventional rotary-head drilling [16].

Several studies have conducted drilling operations with electropulse methods $[17,16,15]$, or performed separate investigations of the mechanisms underlying disintegration of the solid material [4, 12, 9]. Budenstein [12] performed experiments indicating the development of a gaseous channel through the solid material during breakdown. Once a conductive channel is created, streamer formation occurs, and subsequent enlargement of a conductive path further increases electrical conductivity and permittivity [5]. Disintegration of the solid material itself is induced by the expansion of the gas channels and minerals due to high temperature and pressure. From the solid's perspective, the rapid expansion of streamer channels causes stress perturbations that exceed the tensile strength of the material $[5,17,18,16]$. Lisitsyn et al. [9] describe the rock disintegration process as expansion of vapor-gas cavities in the solid material during breakdown, which then leads to a pressure wave through the solid material.

Nevertheless, the description of the pulse behaviour and its effect on the rock remains largely empirical [19, 20]. Design of tool-head configurations and selection of pulse size and duration is challenging without a quantitative model, and prediction of tool behaviour difficult under extreme circumstances (for example, under the pressures and temperatures encountered at depth).

In this paper, we outline an approach to simulate the coupled processes involved in electropulse stimulation of hard rocks. The model simulates the passage of the pulse through the rock microstructure and captures the subsequent electric breakdown. Subsequent heating and damage to the rock mass is represented by tracking the mechanical behaviour of the rock following the pulse discharge. The new model can be used to interrogate the effects of different grain sizes and material compositions on the electropulse stimulation, allowing tool designers to optimize their operation under a range of real world conditions. In the following sections, we present the components of the model and give examples illustrating the effect of different conditions on the passage of the pulse. 


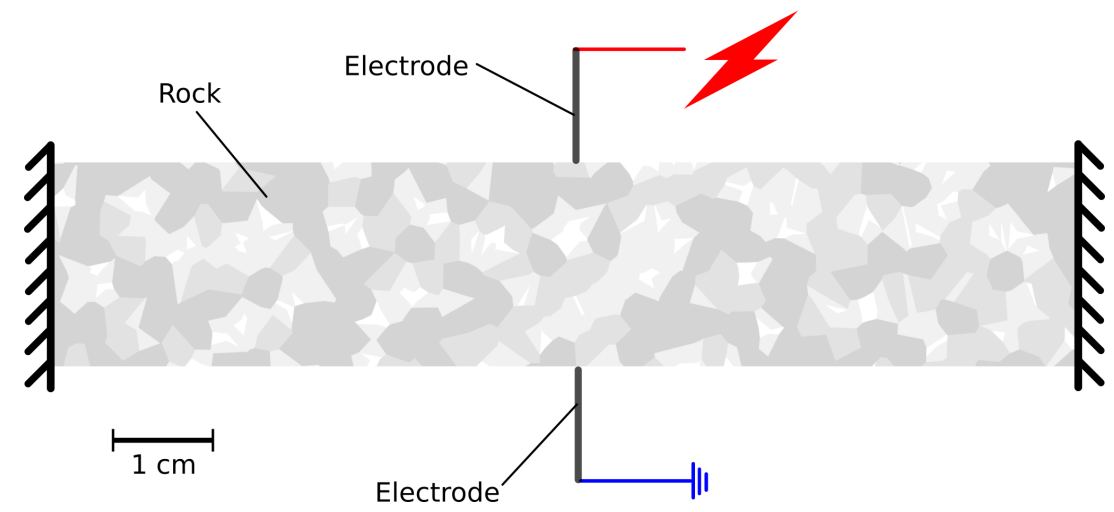

Figure 1: Simulation geometry and boundary conditions.

\section{Model description}

Here, we describe the components used to model electropulse stimulation (as illustrated in Figure 1). The goal of the simulation is to represent the path of the high voltage current through the granitic rock, and its subsequent effect on the rock matrix. The numerical model is simulated with the multiphysics finite element solver MOOSE, developed by Idaho National Laboratory [21]. MOOSE's open source platform provides a convenient framework in which to couple the competing physical processes. In this section, we outline the components of the numerical model and the method used to generate the rock microstructure.

The electropulse simulation involves a series of coupled processes: i) the electrical discharge and accompanying resistive heating of the rock; followed by ii) conduction of heat away from the discharge path and the mechanical response of the sample to the induced thermal load. While all four processes are coupled, they act on different timescales, which allows the simulation to be divided into two separate calculations.

The first part of the calculation models the passage of the electric pulse through the rock body. As in other high voltage studies [22, 23, 24], we assume that the electrical discharge can be modeled as a quasi-static process where the current per unit area, $J_{i}$, is related to the electric field $E_{i}$ by Ohm's law:

$$
J_{i}=\Lambda_{i j} E_{j}=\Lambda_{i j} \phi_{, j}
$$

in which $\Lambda_{i j}$ is the electrical conductivity, and $\phi$ is the electrical potential 
field. Here Einstein summation is used, in which summation is implied over repeated indices and a comma is used to represent a gradient along the associated axis, e.g. $\phi_{, i}=\frac{\partial \phi}{\partial x_{i}}$.

Conduction of electricity through a mineral component gives rise to resistive dissipation, described by

$$
\frac{\partial q_{D}}{\partial t}=\Lambda_{i j} \phi_{, i} \phi_{, j}
$$

where $q_{D}$ is the amount of energy transferred to the component. The dissipated energy increases the temperature of the rock according to

$$
\Delta \theta=q_{D} /\left(c_{p} \rho\right)
$$

where $\Delta \theta$ is the temperature increase, $c_{p}$ is the specific heat capacity and $\rho$ is the density. Here, we assume that all dissipated energy is converted into thermal energy, though in practice additional energy is dissipated as sound or light.

Heating changes a material's electrical conductivity. The relationship between temperature and conductivity is a complex function of the material composition and molecular structure. Nevertheless, for solid materials it is often represented using empirical functions of the form:

$$
\Lambda=A \exp \left(-B / k_{b} \theta\right)
$$

or

$$
\Lambda \theta=A \exp \left(-B / k_{b} \theta\right)
$$

where $A$ and $B$ are empirical constants, $\theta$ is the temperature in Kelvin, $-E$, $k_{b}$ is Boltzmann's constant $(8.618 \mathrm{e}-5 \mathrm{eV} / \mathrm{K})[25]$. The values of the empirical parameters used in these simulations are given in Table 1 and plots of the functions are given in Figure 2.

At low temperatures, a rock's electrical conductivity is dominated by the water in micropores and fractures. We model the electrical conductivity of the pore fluid with a combination of empirical models. Sinmyo and Keppler [27] give the following empirical expression for $\mathrm{NaCl}$ solutions:

$\log _{10} \Lambda_{\text {Brine }}=-1.7060-93.78 / \theta+0.8075 \log _{10} c+3.0781 \log _{10} \rho+\log _{10}\left(\lambda_{0}(\rho, \theta)\right)$ 
Table 1: Parameters used in Conductivity/Temperature models for different grain types.

\begin{tabular}{lcccc}
\hline Mineral & Conductivity model & $\log (\mathrm{A})[\log (\mathrm{S} / \mathrm{m})]$ & $\mathrm{B}[\mathrm{eV}]$ & Source \\
\hline Quartz & Equation 5 & 6.3 & 0.82 & {$[25]$} \\
Plageoclase & Equation 4 & 0.041 & 0.85 & {$[25]$} \\
K-Feldspar & Equation 4 & 0.11 & 0.85 & {$[25]$} \\
Biotite & Equation 4 & -13.8 & 0 & {$[26]$} \\
\hline
\end{tabular}

where $\theta$ is the temperature in Kelvin $\rho$ is the density in $\mathrm{g} / \mathrm{cm}^{3}, c$ is the weight $\%$ concentration of $\mathrm{NaCl}$, and $\lambda_{0}$ is the molar conductivity of $\mathrm{NaCl}$ in water at infinite dilution, approximated by

$$
\lambda_{0}=1573-1212 \rho+537062 / \theta-208122721 / \theta^{2} .
$$

However, Equation 6 is invalid for temperatures below $100^{\circ} \mathrm{C}$. Nevertheless, up to $200^{\circ} \mathrm{C}$ electrical conductivity is well approximated by Arps law [28, 29]. Accordingly, we use Arps law [28] to calculate the electrical conductivity for temperatures below $150^{\circ} \mathrm{C}$ :

$$
\Lambda_{\theta}=\Lambda_{\theta_{\text {ref }}} \frac{\theta-251.65}{\theta_{\text {ref }}-251.65}
$$

where $\Lambda_{\theta_{\text {ref }}}$ is the electrical conductivity at the reference temperature $\theta_{\text {ref }}$ in Kelvin. For the simulations shown in this paper, we set $\theta_{\text {ref }}$ to $150^{\circ} \mathrm{C}$. The offset of $251.65 \mathrm{~K}$ used in Equation 8 is based on the value given in [30].

To capture the effect of the pore fluid fraction on the bulk conductivity, we introduce the following two-component-mixture model based on Glover's extension to Archie's law [31, 32],

$$
\Lambda_{m i x}=\Lambda_{s}\left(1-\varphi_{f}\right)^{p}+\Lambda_{f} \varphi_{f}^{m}
$$

where $\Lambda_{m i x}$ is the conductivity of the composite body, $\Lambda_{s}$ the conductivity of the solid phase, and $\Lambda_{f}$ is the conductivity of the fluid; $\varphi_{f}$ is the fluid volume fraction, $m$ is Archie's exponent, and $p=\log \left(1-\varphi_{f}^{m}\right) / \log \left(1-\varphi_{f}\right)$. For the granitic rock, we assume a value of 1.5 for Archie's exponent $(m)$ based on measured values quoted in [33].

Glover's mixture model assumes that each component effectively acts as a separate conducting pathway, i.e. each component can be approximated as 
conducting the electrical charge in parallel. For this model, we also assume that during the rapid pulse discharge the heat generated in the two phases acts in the same manner. Thus, during the discharge we calculate the resistive heating of the fluid and solid phases from:

$$
\begin{aligned}
\frac{\partial q_{f}}{\partial t} & =\varphi_{f}^{m} \Lambda_{f} \delta_{i j} \phi_{, i} \phi_{, j} \\
\frac{\partial q_{s}}{\partial t} & =\left(1-\varphi_{f}\right)^{p} \Lambda_{s} \delta_{i j} \phi_{, i} \phi_{, j},
\end{aligned}
$$

where $q_{f}$ is the dissipative heat transferred to the fluid, $q_{s}$ is the dissipative heat transferred to the solid. The resulting change in the individual component temperatures is governed by:

$$
\begin{aligned}
\Delta \theta^{f} & =q_{f} /\left[c_{p}^{f} \rho_{f} \varphi_{f}\right], \\
\Delta \theta^{s} & =q_{s} /\left[c_{p}^{s} \rho_{s}\left(1-\varphi_{f}\right)\right] .
\end{aligned}
$$

where $c_{p}^{f}$ is the heat capacity of the fluid phase, $c_{p}^{s}$ is the heat capacity of the solid phase, $\rho_{f}$ is the density of the fluid and $\rho_{s}$ is the density of the solid. When modeling thermal diffusion between discharges in the second stage of the simulation, we calculate the initial temperature increase of the mixed material from

$$
\Delta \theta=\left(q_{f}+q_{s}\right) /\left[c_{p}^{f} \rho_{f} \varphi_{f}+c_{p}^{s} \rho_{s}\left(1-\varphi_{f}\right)\right] .
$$

Microporosity is not evenly distributed throughout rock. Studies by [34], for example, noted a propensity for micropores to concentrate in plagioclase grains. For the purpose of this study we assume the initial micro-porosity is distributed according to Table 2, which contains values are based on measured microporosities in granite from Montgomery [34].

For small pores in granite the conductivity is enhanced by surface conduction effects - this decreases the apparent resistivity to around $2 \Omega / m$ [35] even for pores with dilute solutions. For pores containing higher salinity fluid the surface effect is reduced leaving the effective conductivity unchanged. For these simulations, we assume that the pore fluid has an effective salinity of $3 \mathrm{wt} \%$ [36].

Feedback between the path of the electrical pulse and subsequent changes in conductivity may result in channeling of the current through the sample, resulting in further heating and the breakdown of its dielectric properties [37, 


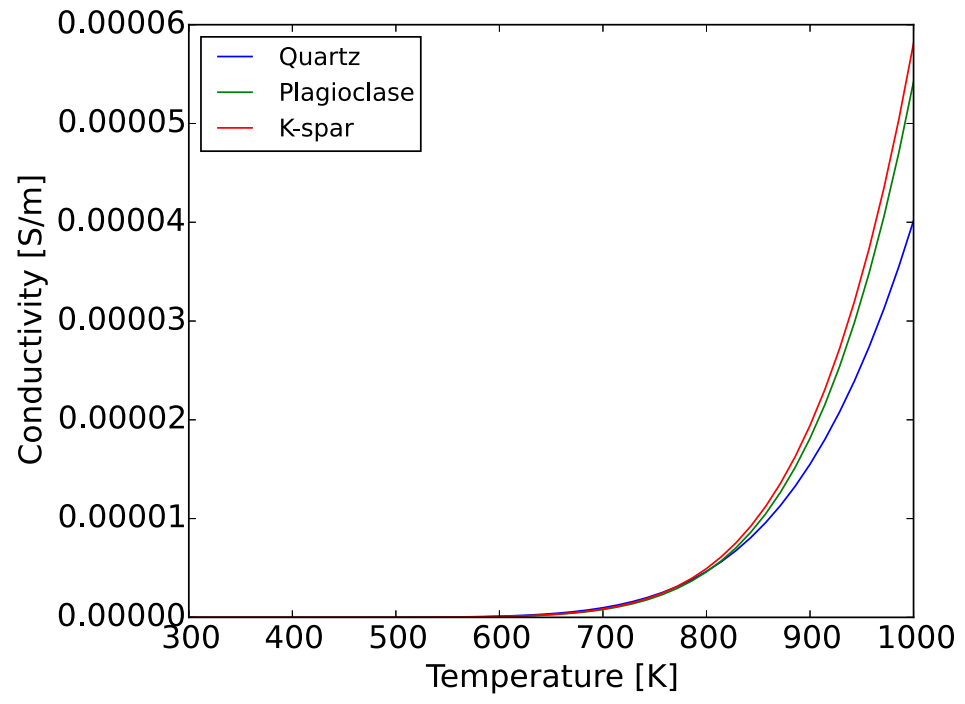

Figure 2: Conductivity-temperature relationships employed for the minerals considered in the simulations.

Table 2: Microporosity in quartz, K-feldspar, plagioclase and biotite minerals [34].

\begin{tabular}{cccccc}
\hline & Quartz & Plageoclase & K-Feldspar & Biotite \\
\hline Microporosity & {$[\%]$} & 0.9 & 1.8 & 0.9 & 0.9 \\
\hline
\end{tabular}


38]. This is simulated in the model as thermal breakdown, caused by feedback between the flow of current and increasing conductivity with temperature in the rock. It should be noted that there are several competing theories as to the precise nature of breakdown phenomena [see, for example, discussions in 39,38$]$. Some researchers postulate that breakdown on small timescales is purely electrical in nature, while others have theorized that thermal or mechanical effects must ultimately still play a role. Moreover, in many cases these theories have been proposed to describe phenomena either on atomic scales too small for the present simulation or on larger scales more applicable to insulators than the present grain-scale of interest. In the absence of an established rule, we employ a model of thermal breakdown to describe the breakdown process, and assume that the thermal breakdown is sufficient to establish the path, if not the exact mechanism of breakdown within the rock body. This approach and underlying assumptions are similar to those employed elsewhere to simulate of lightning strikes on composite materials in aircraft and wind generators [e.g. 40, 41].

Once the pulse has been simulated, we represent its effect on the rock by simulating the resulting thermomechanical behaviour. This second stage of the simulation involves resolving the conduction of heat through the rock and any subsequent changes in the stress field due to thermally induced stresses.

Transmission of heat in the sample is governed by thermal diffusion:

$$
c_{p} \rho \frac{\partial \theta}{\partial t}=\left(\kappa \theta_{, i}\right)_{, i}
$$

where $\kappa$ is the thermal conductivity.

The mechanical response to the heating is represented in the simulation by a linear thermal strain of the form:

$$
\epsilon_{i j}^{\text {thermal }}=\alpha\left(\theta-\theta_{r e f}\right) \delta_{i j},
$$

where $\theta_{\text {ref }}$ is a reference temperature and $\alpha$ is the thermal expansion coefficient, and $\delta_{i j}$ is the Kronecker delta tensor. Thermal stresses, $\sigma^{\text {thermal }}$, are calculated from:

$$
\sigma_{i j}^{\text {thermal }}=C_{i j k l} \epsilon_{k l}^{\text {thermal }} .
$$

where $C_{i j k l}$ is the stiffness tensor.

\subsection{Failure criteria}

This study uses a failure criteria to determine the onset and type of damage. The damage model was originally proposed by Diederichs et al. 
$[42,43]$ to model the onset of rock surface damage in the form of spalling. The model was then tested against experimental data of hard rocks on both the laboratory and field scale $[42,44]$.

The damage model distinguishes Hoek-Brown failure (originally developed for intact rock specimens), spalling failure (formulated for pre-damaged rock masses) and tensile failure $[45,46]$. Hoek-Brown failure indicates failure of intact rock specimen under confinement, and can be expressed as:

$$
\sigma_{1}^{\prime}=\sigma_{3}^{\prime}+\sigma_{c}\left(m \frac{\sigma_{3}^{\prime}}{\sigma_{c}}+s\right)^{a},
$$

with maximum and minimum principal stresses $\sigma_{1}^{\prime}$ and $\sigma_{3}^{\prime}$, the standard uniaxial compressive strength (UCS) $\sigma_{c}$, the slope constant of the HoekBrown criterion $m$, and rock mass specific constants $s$ and $a$. Conversely, spalling failure does not assume an intact rock mass, and denotes a strength limit lower than the Hoek-Brown envelope. This holds true for brittle failure and crack propagation in pre-damaged and jointed rock masses. Spalling failure specifically occurs near free surfaces (i.e. low confinement) where the rock mass may yield at lower thresholds than expected for an intact rock mass under confinement $[42,44]$. This is further supported by the respective stress-strain history that excavated rock is exposed to, in contrast to intact rock specimens commonly used for laboratory testing [44]. It should be noted that failure at the spalling limit depends on the state of the rock mass, local heterogeneities or weaker minerals causing strain localization and tensile stresses $[47,48,42]$ and pre-existing damage.

When distinguishing tensile and compressive minimum principal stresses for Hoek-Brown and spalling failure, this yields the following five damage modes: 1) Tensile failure; 2) Spalling failure under tension; 3) Spalling failure under compression; 4) Failure by surpassing the long-term strength of lab specimen under tension; and 5) Failure by surpassing the long-term strength of lab specimen under compression [42, 43, 44, 49]. If rock is predicted to fail under these failure modes, the respective regions indicate the creation of local flaws, which then serve as nucleation sites for the propagation of larger cracks which then lead to the removal of flakes from the rock mass.

The following model parameters are assumed for this study: $s$ is $1 ; a$ is $0.5 ; \sigma_{c}$ is $122 \mathrm{MPa}$; the Hoek-Brown value, $m$, is $25 \mathrm{MPa}$; the tensile strength $\sigma_{t}$ is $10 \mathrm{MPa}$ and the spalling limit $\left(\sigma_{1} / \sigma_{3}\right)$ is assumed to be 8 (denoting the lower spalling limit of previous studies) [50, 47, 44, 51, 52]. 


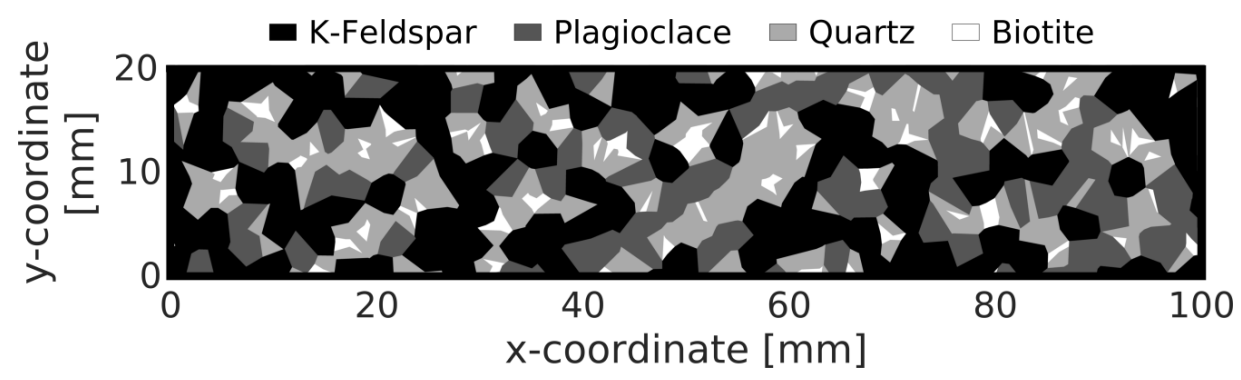

Figure 3: Material microstructure with different grain size and volumetric percentage for K-Feldspar, Plagioclase, Quartz and Biotite.

\subsection{Material composition}

The material microstructure used in the simulations considered here has a rock composition and grain-size distribution typical of granite [53] (Table 3). Granitic rock is representative of hard rocks, which are notoriously costly to process with mechanical means, and have also been frequently used to study novel drilling and cutting techniques [54, 47, 55, 56, 57, 58].

A Voronoi tesselation is used to generate the rock microstructure, with the Voronoi cells representing individual mineral grains (Figure 3). To obtain the desired volumetric percentage and grain size of each of the mineral types, initially randomly distributed cell volumes were iteratively relaxed until the desired material composition was achieved [59, 60,61]. The rock composition properties are shown in Table 3, and the generated material microstructure is shown in Figure 3.

Table 3: Rock composition with volumetric percentage (vol\%) of different mineral phases and grain size distributions obtained from Lac du Bonnet granite [53].

\begin{tabular}{lccccccccc}
\hline Rock & \multicolumn{3}{c}{ K-Feldspar } & \multicolumn{3}{c}{ Plagioclase } & \multicolumn{2}{c}{ Quartz } & \multicolumn{2}{c}{ Biotite } & Source \\
type & vol\% & size & vol\% & size & vol\% & size & vol\% & size & \\
& {$[\%]$} & {$[\mathrm{mm}]$} & {$[\%]$} & {$[\mathrm{mm}]$} & {$[\%]$} & {$[\mathrm{mm}]$} & {$[\%]$} & {$[\mathrm{mm}]$} & \\
\hline Granite & 45 & 3.7 & 20 & 3.1 & 30 & 1.8 & 5 & 0.9 & {$[53]$} \\
\hline
\end{tabular}

\section{Results}

For these simulations a single pulse is applied between two electrodes on either side of a sample with $2 \mathrm{~cm}$ thickness and $10 \mathrm{~cm}$ width, as illustrated 
in Figure 1. The sample is clamped at each end $(x=0$ and $x=100 \mathrm{~mm})$. The $600 \mathrm{kV}$ pulse is applied across the center of the sample $(x=50 \mathrm{~mm})$ for a duration of 2 microseconds. The pulse durations and voltages are representative of experimental ranges described in $[13,14,19,15]$. They provide a test to see whether the heat dissipated into the rock is sufficient to generate the rock failure observed in experiments.

The applied pulse generates an electric potential $\phi$ across the center of the sample (Figure 4). The associated electric field $E_{i}=\phi_{, i}$ shows preferential paths through minerals and on throats of connecting minerals (Figure 5c). The electrical conductivity of the mixed material is derived with the mixing rule described in Eq. 14 and represents both increases in electrical conductivity of the fluid and solid. The electric current per unit area $J_{i}$ (equation 1) can then be determined by multiplying the electrical conductivity in the minerals $\lambda_{m}$ and $\phi_{, j}$ (Figure 5b-d). ${ }^{1}$

Preferential channels can readily be observed for the electric current per unit area $J_{i}$ (Figure $5 \mathrm{~d}$ ), with two main channels in the center of the sample, and preferential channeling to the left and right of the electrode on the bottom of the sample. To understand the processes which yield preferential currents in the rock mass shown in Figure 5d, one has to consider the material parameters which differentiate the different minerals. Most notably, in these simulations plagioclase is given a higher volumetric pore fluid content, which can result in higher electrical conductivities if the pore fluid is sufficiently conductive. At the same time, the plagioclase itself has the lowest electrical conductivity in the solid for the starting temperature, and would therefore need to be heated up significantly for the solid domain to become more conductive than the solid phases of the other minerals. As can be seen in Figures $5 \mathrm{~d}$ and $6 \mathrm{a}-\mathrm{b}$, however, electrical conductivity of the fluid dominates overall conductivity for the initial temperature in the rock mass (Figure 6a-b, left column). Even for early time steps, when the material has not been heated sufficiently (Figure 6c, left) which means that electrical conductivities have not undergone significant temperature related changes, the electrical conductivity of the material mix $\lambda_{m}$ shows higher conductivity in the plagioclase

\footnotetext{
${ }^{1}$ It should be noted that the current is a byproduct of the voltage drop applied across the sample, which in reality would itself depend on the discharge from the electropulse device. Here, as we are primarily interested in modelling the passage of the discharge through the rock we have not explicitly modelled the device response - assuming a constant voltage drop for the pulse duration.
} 
mineral phase (Figure 6b, left). This causes smaller electrical resistance and therefore lower gradients of the electrical field $\phi_{, j}$ (Figure 6d, left), as well as the characteristic higher fluxes observed through plagioclase minerals (Figure 6 e, left).

As electrical conductivity in the other minerals is low in the beginning, but plagioclase does not offer a connected path between the two electrodes, current has to flow through other minerals with a higher resistivity, thereby heating those regions by dissipating energy. With the electric current predominantly conducted through the fluid phase, the increasing temperature in those regions increases the electrical conductivity in the fluid phase $\lambda_{f}$ (Figure $6 a, c$, middle and right). While this increase in $\lambda_{f}$ occurs more rapidly in non-plagioclase minerals (Figure 6a, middle and right), the electrical conductivity in the mixed material $\lambda_{m}$ is still higher in plagioclase, since the mixing rule for $\lambda_{m}$ accounts for the significantly higher volumetric pore fluid content of plagioclase.

For the drilling process to work, the material needs to fail through the above mentioned processes, which can occur by increases in temperature that lead to sample deformation and increased stresses. These stresses can be used to estimate regions where damage will be initiated in the rock mass, once the strength of the material is exceeded. The temperature increases caused by energy dissipation can be seen in electricity conduction (Figure 5c). Here, the regions around the electrodes see a significant increase in temperature, which can be explained with the steep gradient of the electric field in this region (see Figure 5f). While the material is heated up significantly in the rock mass between the electrodes, only the immediate region around the electrodes sees temperature increases of more that $200 \mathrm{~K}$. Under the conditions applied in this study, a single pulse is sufficient to generate a localized pathway through the rock, heating it and causing it to fracture. As shown in Figure 5g, the damage produced by the pulse is concentrated in the region around the two electrodes.

Specifically, the dominant damage mechanisms (see Section 2.1) observed around the electrodes are tensile failure (damage mode 1), spalling failure under tension and compression (damage modes 2 and 3), and failure by surpassing the long-term strength of lab specimen under tension (damage mode 4). As would be expected, spalling failure occurs near the surfaces, where it can lead to the rapid removal or larger "spalls" or disk shaped fragments of the rock. Further into the rock mass, larger regions of tensile failure damage mode are observed. While the rock layer on the surface is 


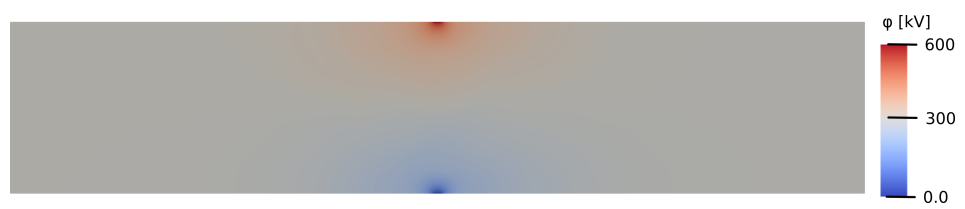

Figure 4: Distribution of the electrical field in the sample between the electrodes placed in the center at the top and bottom of the sample. The time step shown is $2 \mu s$ following the electrical discharge.

expanding due to heating, this causes regions of tensile stress near the surface, with regions of larger tensile stresses subsequently yielding to tensile failure. Damage region of tensile long-term laboratory specimen failure occur the deepest in the rock mass, but are locally clustered.

Regardless of the material composition, the regions near the electrodes experience the largest gradients in the electric field, which results in larger electric currents and energy dissipation. The energy dissipation ultimately heats the material, which causes thermal strains and finally material failure. The larger damage regions on the bottom of the domain are caused by the different mineralogy near the electrodes (Figure 5a and g). At the top of the domain, the electrode touches a plagioclace grain, while the electrode on the bottom of the domain touches a K-feldspar grain. This results in a higher electric conductivity near the top electrode (Figure 6b, left) and therefore less energy dissipation and temperature increase (Figure 5f), which consequently results in smaller thermal strains and ultimately smaller damage regions.

The presented approach indicates regions that will or (in the case of spalling) are most likely to fail. Once individual flaws occur in the material, the dominating mechanism can change to that of a propagating crack, which ultimately results in the removal of rock mass required for successful drilling operation. Failure in this study is confined to the onset of damage, since crack propagation from multiple, interacting cracks in regions of damage is beyond the scope of this paper. However, the results in Figure $5 \mathrm{~g}$ show that the presented approach indicates whether the applied electric field will cause failure for the rock mass investigated.

\section{Conclusion}

In this paper, we have demonstrated a new approach to modelling electropulse stimulation of rock. The new model explicitly accounts for the 


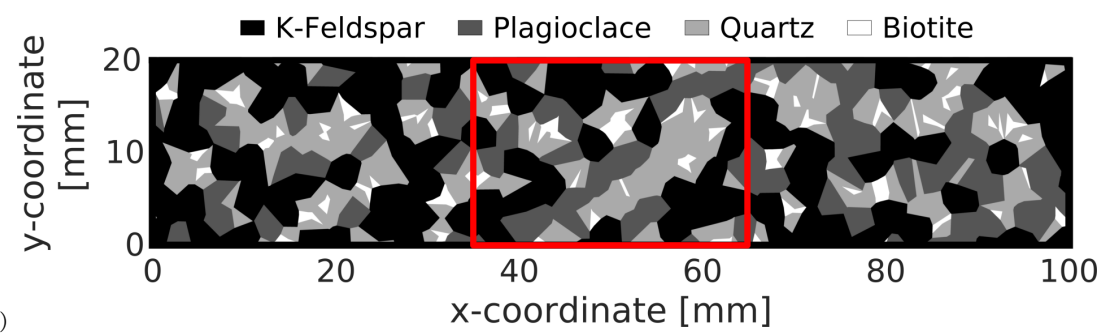

a)
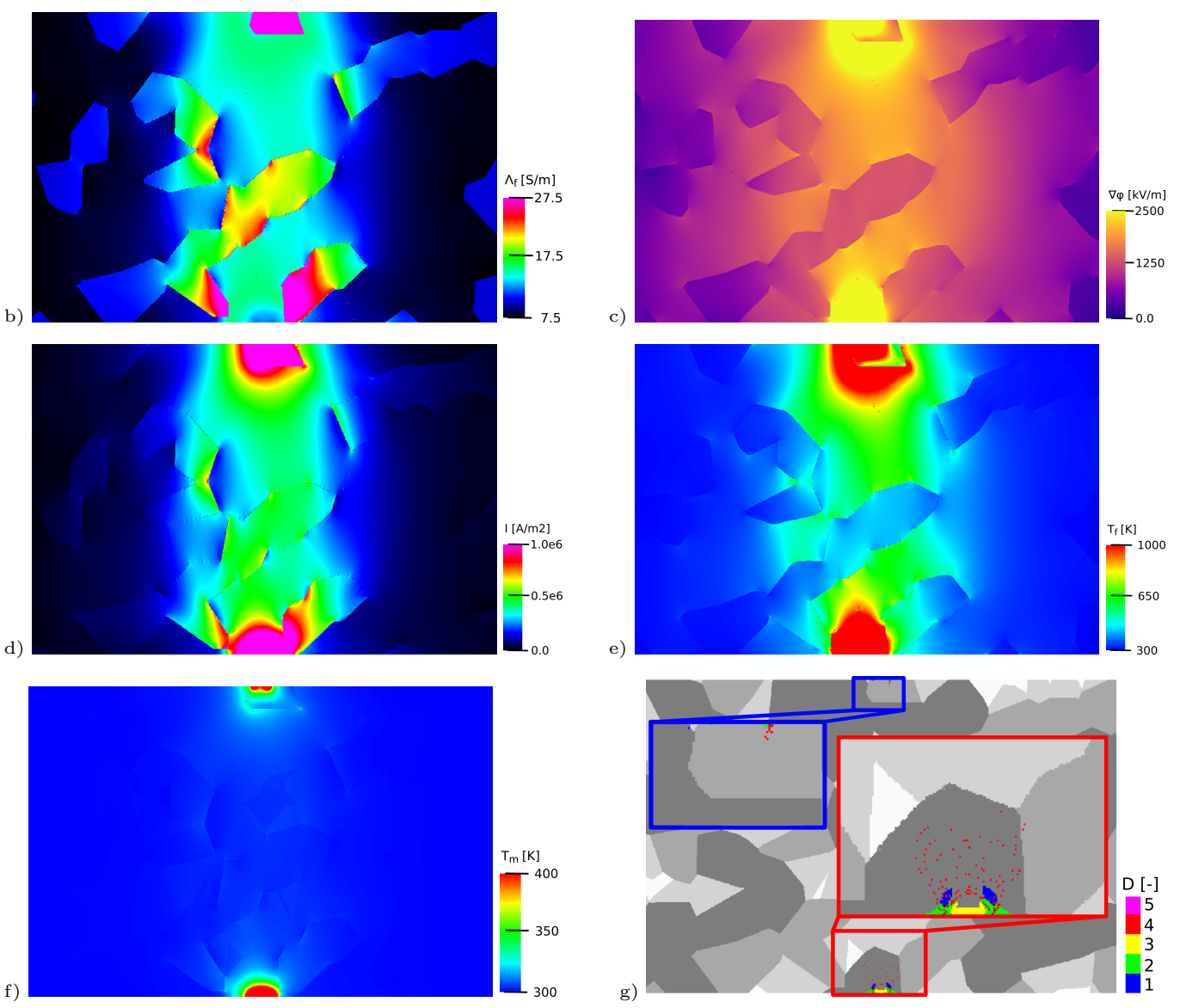

Figure 5: a) Subregion shown in the plotted graphs marked in red; b) Electrical conductivity of the material $\lambda_{m}$; c) Electric field $\left|\phi_{, j}\right| ;$ d) Current; e) Temperature of the fluid $T_{f}$; f) Temperature of the material $T_{m}$; and $\mathrm{g}$ ) Damaged regions, superposed on the system domain. 


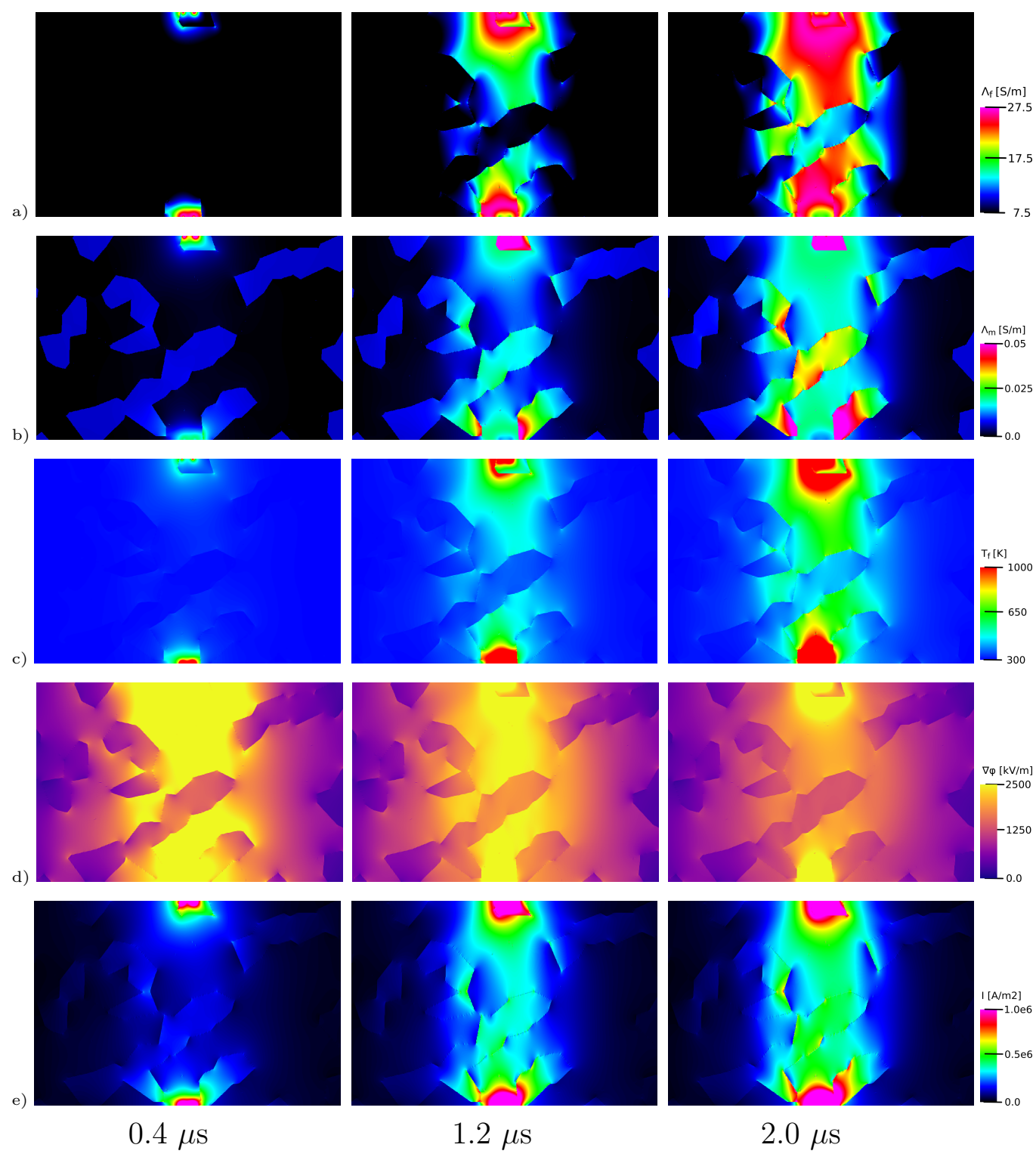

Figure 6: Time series for $0.4,1.2$ and $2.0 \mu \mathrm{s}$ for: a) Electrical conductivity of the fluid $\lambda_{f}$; b) Electrical conductivity of the material mix $\lambda_{m}$; c) Temperature of the fluid $T_{f}$; d) Electric Field $\left|\phi_{, j}\right| ;$ and e) Electric current $J_{i}$. 
material microstructure and the influence of both minerals and micropores on the electrical conductivity. It couples the discharge of the high voltage electrical current with the subsequent mechanical response of the rock by dividing the calculation into two stages.

In the first stage, the dielectric breakdown of the rock is modelled by tracking the feedback between resistive heating and the increase in electrical conductivity. Due to the large disparity in conductivity between the minerals and the fluid within micropores, the rock is simulated as a "dualconductivity" material. As a result the fluid temperature increases more rapidly during the initial discharge, and the microporosity distribution dominates the electical discharge during initial breakdown.

In the second stage of the simulation the effect of the heating on the rock is simulated by tracking the thermomechanical response of the sample. The simulations successfully replicate the onset of fragmentation under similar conditions to those observed in experiments. As a result of the local heating, the rock is fractured under a combination of tensile load and spalling failure in the immediate vicinity of the electrode. Results from the model were compared with those from experimental studies and shown to predict breakdown and damage under similar operating conditions. The new numerical model enables the investigation of the effects of mineral composition, applied voltage and insitu stresses on the performance of electropulse drilling operations.

\section{Acknowledgements}

D.V. was supported by Innosuisse - The Swiss Innovation Agency.

\section{References}

[1] J. W. Tester, B. J. Anderson, A. S. Batchelor, D. D. Blackwell, R. DiPippo, E. M. Drake, J. Garnish, B. Livesay, M. C. Moore, K. Nichols,

et al., Impact of enhanced geothermal systems on us energy supply in the twenty-first century, Philosophical Transactions of the Royal Society A: Mathematical, Physical and Engineering Sciences 365 (2007) 1057-1094.

[2] J. Biela, C. Marxgut, D. Bortis, J. W. Kolar, Solid state modulator for plasma channel drilling, in: 2008 IEEE International Power Modulators and High-Voltage Conference, pp. 423-426. 
[3] H. Bluhm, W. Frey, H. Giese, P. Hoppe, C. Schultheiss, R. Strassner, Application of pulsed hv discharges to material fragmentation and recycling, IEEE Transactions on Dielectrics and Electrical Insulation 7 (2000) 625-636.

[4] U. Andres, Liberation study of apatite-nepheline ore comminuted by penetrating electrical discharges, International Journal of Mineral Processing 4 (1977) 33-38.

[5] U. Andres, I. Timoshkin, J. Jirestig, H. Stallknecht, Liberation of valuable inclusions in ores and slags by electrical pulses, Powder Technology 114 (2001) 40-50.

[6] M. He, J. Jiang, G. Huang, J. Liu, C. Li, Disintegration of rocks based on magnetically isolated high voltage discharge, Review of Scientific Instruments 84 (2013) 024704.

[7] W. Zuo, F. Shi, E. Manlapig, Electrical breakdown channel locality in high voltage pulse breakage, Minerals Engineering 69 (2014) 196-204.

[8] W. Zuo, A study of the applications and modelling of high voltage pulse comminution for mineral ores, Ph.D. thesis, PHD thesis, University of Queensland, JKMRC. 206pp. Brisbane, Australia, 2015.

[9] I. V. Lisitsyn, H. Inoue, I. Nishizawa, S. Katsuki, H. Akiyama, Breakdown and destruction of heterogeneous solid dielectrics by high voltage pulses, Journal of Applied Physics 84 (1998) 6262-6267.

[10] K. Uenishi, N. Shigeno, S. Sakaguchi, H. Yamachi, J. Nakamori, Controlled disintegration of reinforced concrete blocks based on wave and fracture dynamics, Procedia Structural Integrity 2 (2016) 350-357.

[11] J. Chen, C. Elmi, D. Goldsby, R. Gieré, Generation of shock lamellae and melting in rocks by lightning-induced shock waves and electrical heating, Geophysical Research Letters 44 (2017) 8757-8768.

[12] P. P. Budenstein, On the mechanism of dielectric breakdown of solids, IEEE Transactions on Electrical Insulation (1980) 225-240.

[13] H. Inoue, I. V. Lisitsyn, H. Akiyama, I. Nishizawa, Pulsed electric breakdown and destruction of granite, Japanese journal of applied physics 38 (1999) 6502. 
[14] H. Inoue, I. V. Lisitsyn, H. Akiyama, I. Nishizawa, Drilling of hard rocks by pulsed power, IEEE Electrical Insulation Magazine 16 (2000) $19-25$.

[15] E. Anders, M. Voigt, F. Lehmann, M. Mezzetti, Electric impulse drilling: The future of drilling technology begins now, in: ASME 2017 36th International Conference on Ocean, Offshore and Arctic Engineering, American Society of Mechanical Engineers, pp. V008T11A024-V008T11A024.

[16] M. Voigt, E. Anders, F. Lehmann, et al., Electric impulse technology: Less energy, less drilling time, less round trips, in: SPE Asia Pacific Oil \& Gas Conference and Exhibition, Society of Petroleum Engineers, pp. $1-9$.

[17] V. F. Vazhov, S. Y. Datskvich, M. Y. Zhurkov, V. M. Muratov, Electric pulse breakdown and rock fracture in a coupled environment of increased pressure and temperature, in: Journal of Physics: Conference Series, volume 552, IOP Publishing, p. 012050.

[18] W. Zuo, F. Shi, E. Manlapig, Electrical breakdown channel locality in high voltage pulse breakage, Minerals Engineering 69 (2014) 196-204.

[19] U. Andres, Parameters of disintegration of rock by electrical pulses, Powder Technology 58 (1989) 265-269.

[20] W. Zuo, F. Shi, E. Manlapig, Modelling of high voltage pulse breakage of ores, Minerals Engineering 83 (2015) 168-174.

[21] D. Gaston, C. Newman, G. Hansen, D. Lebrun-Grandie, Moose: A parallel computational framework for coupled systems of nonlinear equations, Nuclear Engineering and Design 239 (2009) 1768-1778.

[22] T. Ogasawara, Y. Hirano, A. Yoshimura, Coupled thermalelectrical analysis for carbon fiber/epoxy composites exposed to simulated lightning current, Composites Part A: Applied Science and Manufacturing 41 (2010) 973-981.

[23] G. Abdelal, A. Murphy, Nonlinear numerical modelling of lightning strike effect on composite panels with temperature dependent material properties, Composite Structures 109 (2014) 268-278. 
[24] C. Li, L. Duan, S. Tan, V. Chikhotkin, Influences on high-voltage electro pulse boring in granite, Energies 11 (2018) 2461.

[25] J. A. Tyburczy, D. K. Fisler, Electrical properties of minerals and melts, Mineral physics and crystallography, a handbook of physical constants (1995) 185-208.

[26] G. V. Keller, Electrical properties of rocks and minerals, in: Handbook of Physical Properties of Rocks (1982), CRC Press, 2017, pp. 217-294.

[27] R. Sinmyo, H. Keppler, Electrical conductivity of nacl-bearing aqueous fluids to $600 \mathrm{c}$ and $1 \mathrm{gpa}$, Contributions to Mineralogy and Petrology $172(2017) 4$.

[28] J. Arps, et al., The effect of temperature on the density and electrical resistivity of sodium chloride solutions, Journal of Petroleum Technology 5 (1953) 17-20.

[29] H. Ucok, I. Ershaghi, G. R. Olhoeft, et al., Electrical resistivity of geothermal brines, Journal of Petroleum Technology 32 (1980) 717-727.

[30] M. Fleury, H. Deschamps, Electrical conductivity and viscosity of aqueous nacl solutions with dissolved co2, Journal of Chemical \& Engineering Data 53 (2008) 2505-2509.

[31] P. W. Glover, M. J. Hole, J. Pous, A modified archies law for two conducting phases, Earth and Planetary Science Letters 180 (2000) 369-383.

[32] P. W. Glover, A generalized Archies law for $\mathrm{n}$ phases, Geophysics 75 (2010) E247-E265.

[33] H. Pape, L. Riepe, J. Schopper, et al., Petrophysical detection of microfissures in granites, in: SPWLA 26th Annual Logging Symposium, Society of Petrophysicists and Well-Log Analysts, pp. 1-17.

[34] C. W. Montgomery, W. Brace, Micropores in plagioclase, Contributions to Mineralogy and Petrology 52 (1975) 17-28.

[35] W. Brace, Resistivity of saturated crustal rocks to $40 \mathrm{~km}$ based on laboratory measurements, The Structure and Physical Properties of the Earth's Crust 14 (1971) 243-255. 
[36] A. Shimojuku, T. Yoshino, D. Yamazaki, Electrical conductivity of brine-bearing quartzite at 1 gpa: Implications for fluid content and salinity of the crust, Earth, Planets and Space 66 (2014) 2.

[37] J. O'dwyer, Dielectric breakdown in solids, Advances in Physics 7 (1958) 349-394.

[38] K. C. Kao, Dielectric phenomena in solids, Elsevier, 2004.

[39] K. C. Kao, New theory of electrical discharge and breakdown in lowmobility condensed insulators, Journal of applied physics 55 (1984) $752-755$.

[40] T. Ogasawara, Y. Hirano, A. Yoshimura, Coupled thermal-electrical analysis for carbon fiber/epoxy composites exposed to simulated lightning current, Composites Part A: Applied Science and Manufacturing 41 (2010) 973-981.

[41] Y. Wang, Multiphysics analysis of lightning strike damage in laminated carbon/glass fiber reinforced polymer matrix composite materials: A review of problem formulation and computational modeling, Composites Part A: Applied Science and Manufacturing 101 (2017) 543-553.

[42] M. S. Diederichs, P. K. Kaiser, E. Eberhardt, Damage initiation and propagation in hard rock during tunnelling and the influence of nearface stress rotation, International Journal of Rock Mechanics and Mining Sciences 41 (2004) 785-812.

[43] M. S. Diederichs, The 2003 canadian geotechnical colloquium: Mechanistic interpretation and practical application of damage and spalling prediction criteria for deep tunnelling, Canadian Geotechnical Journal 44 (2007) 1082-1116.

[44] F. Rojat, V. Labiouse, P. K. Kaiser, F. Descoeudres, Brittle rock failure in the steg lateral adit of the lötschberg base tunnel, Rock Mechanics and Rock Engineering 42 (2008) 341.

[45] E. Hoek, E. T. Brown, Underground excavations in rock, CRC Press, 1980. 
[46] E. Hoek, E. T. Brown, Practical estimates of rock mass strength, International journal of rock mechanics and mining sciences 34 (1997) $1165-1186$.

[47] R. Rauenzahn, J. Tester, Rock failure mechanisms of flame-jet thermal spallation drillingtheory and experimental testing, International Journal of Rock Mechanics and Mining Sciences \& Geomechanics Abstracts 26 (1989) 381-399.

[48] C. Tang, P. Kaiser, Numerical simulation of cumulative damage and seismic energy release during brittle rock failurepart i: fundamentals, International Journal of Rock Mechanics and Mining Sciences 35 (1998) $113-121$.

[49] D. Vogler, S. D. C. Walsh, P. Rudolf von Rohr, M. O. Saar, Simulation of rock failure modes in thermal spallation drilling, 2019. Submitted.

[50] J. C. Jaeger, N. G. W. Cook, R. W. Zimmerman, Fundamentals of rock mechanics, John Wiley \& Sons, 2009.

[51] T. Kazerani, Effect of micromechanical parameters of microstructure on compressive and tensile failure process of rock, International journal of rock mechanics and mining sciences 64 (2013) 44-55.

[52] D. Vogler, S. D. C. Walsh, P. Bayer, F. Amann, Comparison of surface properties in natural and artificially generated fractures in a crystalline rock, Rock Mechanics and Rock Engineering 50 (2017) 2891-2909.

[53] E. Eberhardt, B. Stimpson, D. Stead, Effects of grain size on the initiation and propagation thresholds of stress-induced brittle fractures, Rock mechanics and rock engineering 32 (1999) 81-99.

[54] R. Rinaldi, A technical and economic evaluation of thermal spallation drilling technology, Dynamics of Fluids in Fractured Rock (1984) 253.

[55] R. M. Rauenzahn, J. W. Tester, Numerical simulation and field testing of flame-jet thermal spallation drilling - 1. model development, International Journal of Heat and Mass Transfer 34 (1991) 795-808.

[56] R. M. Rauenzahn, J. W. Tester, Numerical simulation and field testing of flame-jet thermal spallation drilling - 2. experimental verification, International Journal of Heat and Mass Transfer 34 (1991) 809-818. 
[57] S. D. C. Walsh, I. N. Lomov, T. W. Wideman, J. M. Potter, Size dependent spall aspect ratio and its effects in thermal spallation, International Journal of Rock Mechanics and Mining Sciences (2014) 375-380.

[58] M. A. Kant, E. Rossi, C. Madonna, D. Höser, P. Rudolf von Rohr, A theory on thermal spalling of rocks with a focus on thermal spallation drilling, Journal of Geophysical Research: Solid Earth 122 (2017) 18051815 .

[59] S. D. C. Walsh, I. N. Lomov, Micromechanical modeling of thermal spallation in granitic rock, International Journal of Heat and Mass Transfer 65 (2013) 366-373.

[60] S. D. C. Walsh, Modeling thermally induced failure of brittle geomaterials, Technical Report, Lawrence Livermore National Laboratory, 2013.

[61] J. P. Singh, S. D. C. Walsh, D. L. Koch, Brownian dynamics of a suspension of particles with constrained voronoi cell volumes, Langmuir 31 (2015) 6829-6841. 